\title{
Bangladesh: Poverty Reduction Strategy Paper_Joint Staff Advisory Note
}

The attached Joint Staff Advisory Note (JSAN) on the Poverty Reduction Strategy Paper for Bangladesh, prepared jointly by the staffs of the World Bank and the IMF, was distributed with the member country's Poverty Reduction Strategy Paper (PRSP) to the Executive Boards of the two institutions. The objective of the JSAN is to provide focused, frank, and constructive feedback to the country on progress in implementing its Poverty Reduction Strategy (PRS). This country document for Bangladesh is being available on the IMF website by agreement of the member country as a service to users of the IMF website.

Copies of this report are available to the public from

International Monetary Fund • Publication Services $70019^{\text {th }}$ Street, N.W. • Washington, D.C. 20431

Telephone: (202) 623-7430 • Telefax: (202) 623-7201

E-mail: publications@imf.org Internet: http://www.imf.org

\section{International Monetary Fund Washington, D.C.}




\title{
INTERNATIONAL MONETARY FUND AND \\ INTERNATIONAL DEVELOPMENT ASSOCIATION
}

\author{
PEOPLE'S REPUBLIC OF BANGLADESH
}

\section{Joint Staff Advisory Note on the Poverty Reduction Strategy Paper}

\author{
Prepared by the Staffs of the International Monetary Fund \\ and the International Development Association \\ Approved by Kalpana Kochhar and Thomas Dorsey (IMF) \\ and Isabel Guerrero (IDA)
}

April 19, 2010

\section{Introduction}

1. Bangladesh's second Poverty Reduction Strategy Paper - "Steps Towards Change: National Strategy for Accelerated Poverty Reduction II (NSAPR II)" - provides a framework for implementing the government's agenda during FY09-FY11. First prepared by a Caretaker government, ${ }^{1}$ the NSAPR II was later revised by the current elected government to reflect its priorities. The NSAPR II outlines five strategic priorities and describes the supporting strategies to achieve them. This Joint Staff Advisory Note (JSAN) provides feedback on priority areas for strengthening the NSAPR II and its implementation.

2. The NSAPR II is a first step in achieving the government's long-term Perspective Plan. The government is currently preparing a long-term Perspective Plan (2010-2020) to lay out its development vision. To realize this vision, the government will begin implementing the Sixth Five Year Plan (2010-2015) starting July 2010. While the NSAPR II and the Sixth Five Year Plan are expected to overlap significantly, in the staffs' view, a clearer description of how the two fit together would have been useful.

3. All levels of society were consulted during the preparation of NSAPR II. Discussions took place with Central Ministries, local governments, development partners, academia, civil society organizations, and the private sector. For the first time, the NSAPR II was placed before the Parliament. In staffs' view, while the NSAPR II summarizes the consultations, a description of how the feedback was reflected in the final document would have been useful.

4. The NSAPR II provides a basis for improving the effectiveness of aid. At various stages of preparing the strategy, the government consulted the development partners. In addition, the government held the Bangladesh Development Forum in February 2010 during which the NSAPR II was publicly disseminated and formed the basis for discussions with development

1 There is a constitutional provision in Bangladesh for a 90-day transition period between two elected governments to ensure fair elections, during which time the country is run by a caretaker government. For various domestic political reasons, this caretaker government remained in power for two years (20072008). An elected government was formed in January 2009 by the Awami League party. 
partners and the civil society. Staffs concur that the NSAPR II provides a starting point to harmonize and align development assistance with a view to reducing transactions costs for the government. In this respect, it is noteworthy that the NSAPR II makes a reference to the upcoming Joint Cooperation Strategy between government and the development partners.

5. Staffs welcome progress made since the implementation of the first NSAPR in 2005. Real GDP grew on average by 6.2 percent during FY05-09, while per capita incomes rose at an average rate of 4.9 percent. As a result, all available projections point to a decline in poverty during this period. In the area of human development, having attained gender parity in primary and secondary education, Bangladesh is on track to achieving the targets of halving the number of people living below the poverty line, net primary enrolment ratios in primary education and reduction of child mortality. Since 2003, infant and child mortality declined by 20 and 25 percent respectively, outstripping progress in other South Asian countries. This progress was accompanied by substantial narrowing of the gender gap in neonatal, infant and child mortality. Other outcome indicators such as the Doing Business indicators have also shown improvements since 2005. Meanwhile, Bangladesh made progress on the governance front as reflected in improvements in some global governance rankings and a recent National Public Perceptions survey. Political turbulence gave way to elections in December 2008 leading to a peaceful transfer of power. Key reforms during 2005-09 include: improved public financial management through adoption of a medium-term budget framework (MTBF) and generally sound public procurement regime; passage of a Right to Information Act; corporatization of state-owned banks; gains in regulatory reform; and increased local accountability through strengthened local government capacity and the revival of elected local councils.

\section{Poverty diagnostics}

6. In staffs' view, the poverty diagnostic in the NSAPR II is well prepared and of good quality. Using the 2005 Household Income and Expenditure Survey, the NSAPR II provides evidence that Bangladesh made progress in reducing poverty and identifies three main challenges: poverty of women, regional inequality, and extreme and chronic poverty. In addition, the NSAPR II identifies potential causes of these challenges and suggests policy interventions. In staffs' view, given Bangladesh's vulnerability to recurring shocks, the availability of highfrequency poverty estimates is important. Staffs acknowledge that while the projection of poverty estimates in 2009 is a useful exercise to respond to needs for high-frequency poverty data, the reliability of such projections is limited as recognized in the NSAPR II. Therefore, staffs recommend that ways of increasing the frequency of reliable poverty data be explored to enhance the government's capability to respond to shocks in a timely manner.

7. While the NSAPR II provides a good description of poverty diagnostics, it does not analyze the growth and distributional impacts of policies and programs implemented in the past, especially during the first PRSP period. In staffs' view, such an analysis could have sharpened the focus of the NSAPR II and could also form the basis for formulating the forthcoming Sixth Five Year Plan. The NSAPR II should also discuss the mechanisms in place to ensure the Government's annual budget and MTBF are broadly consistent with the strategy's poverty alleviation objectives. 


\section{Priorities and Critical Areas for Success}

\section{A. Pro-Poor Economic Growth}

\section{Macroeconomic framework}

8. The NSAPR II is ambitious in terms of the targeted acceleration of growth, underpinned by higher investment, including additional public investment financed from increased tax revenue. The macroeconomic framework is broadly in line with the reform scenario outlined in the IMF staff report for the 2009 Article IV consultation. If implemented, the NSAPR II's medium-term macroeconomic framework could put the economy on a path to achieve a growth rate of 8 percent as the global economy recovers. However, achieving the ambitious growth targets would require a break from the past, particularly with regard to investing more in infrastructure, alleviating energy constraints, addressing productivity losses arising from unplanned urbanization and improving labor skills. In addition, plans to reform tax policy and administration need to be expedited while capacity constraints and governance issues, which prevent increased implementation of the government's Annual Development Program (ADP), need to be addressed. Here, the immediate challenge is to stem the decline in the public investment rate seen in recent years and raise it to above 5 percent of GDP, as envisaged in the NSAPR II.

9. The critical importance of raising domestic revenue is underscored by the large resource gap projected for the three-year NSAPR II implementation period. The NSAPR II is looking to mobilize US $\$ 12.5$ billion from external sources. However, gross aid disbursements amounted to US\$1.7 billion in FY09 and are not likely to exceed US\$2.5 billion per annum in the coming years. Even for FY10, there may be a shortfall in net financing from external loans and grants compared to the original FY10 budget (2.0 percent of GDP) and the NSAPR II's macroeconomic framework (2.4 percent of GDP). However, under-spending on ADP and Public Private Partnership (PPP) budgets in FY10 is likely to keep domestic borrowing well within the budget target despite a shortfall in net foreign financing in FY10.

10. In staffs' view, the inflation targets set forth in the NSAPR II may be unrealistically low given recent developments and an accommodative monetary policy stance. Currently, private sector credit and broad money growth, at 19.3 and 21.3 percent, respectively, in January 2010 (on a year-on-year basis), are well in excess of targets set in the NSAPR II's macroeconomic framework. These factors, together with recent increases in international commodity prices, may cause inflationary expectations to rise and make it harder to bring inflation under control later, thus putting at risk the NSAPR II's poverty reduction objectives.

11. The uncertain global outlook underscores the importance of government delivering on its domestic reform agenda. Textile and garment exports and workers' remittances have provided important support to domestic demand and poverty reduction in recent years. However, the current weakness in exports and likely slowdown in remittance growth arising from a recent large decline in the number of migrants makes the macroeconomic framework's balance of payments projections appear somewhat optimistic. In this regard, the NSAPR II could have more extensive discussion of trade and trade-related policies, implementation of which is necessary for broadening export base. In the absence of such reforms, the current weakness in exports could put the onus for demand growth squarely on the domestic economy. Thus, the NSAPR II could have paid more attention to the potential contribution of financial sector reform to help secure Bangladesh's growth potential, notably strengthening banks' capital and allowing more flexible interest rates in order to deepen financial markets, building on the recommendations made in the 
joint IMF-World Bank Financial Sector Assessment Program (FSAP) Update in 2009. At the same time, and in view of the relatively modest inflows of foreign direct investment (FDI) into Bangladesh, it is encouraging that the NSAPR II notes that attempts will be made to attract higher FDI inflows by addressing relevant infrastructure bottlenecks. In this context, FDI can also be enhanced by establishing a strong institutional framework for the PPP initiative and by improving the business climate, which is also a condition for successful PPPs.

\section{Private sector development}

12. Overall, staffs welcome the objectives related to the development of the private sector set forth in the NSAPR II and agree that private enterprise should form the basis for sustainable growth and employment in Bangladesh. To create a private-sector friendly environment as well as a pre-condition for PPPs to work, staffs encourage the government to improve the overall investment climate and streamline business regulations to make them less burdensome. Such improvements in the overall investment climate will also help in the growth of the Small and Medium Enterprises, which the NSAPR II considers central to pro-poor growth.

13. Apart from poor infrastructure and burdensome regulations, staffs concur with the NSAPR II that access to finance and availability of land are two important constraints to private sector development. Regarding access to finance, the staffs' view is that making financial markets efficient and inclusive will require a somewhat broader and more systemic approach than outlined in the NSAPR II, along the lines of the recommendations made in the recent update of the FSAP. Staffs encourage further reforms to state-owned banks, increased access to long-term finances, improvements to the regulatory capacity of Bangladesh Bank, and a strengthening of the Securities and Exchange Commission as well as the Micro-Finance Regulatory Authority. Regarding lack of availability of land, staffs agree with the NSAPR II's focus on facilitating efficient land markets and developing modern economic zones to help manage land better as well as to achieve environmentally-and-socially-compliant industrialization. Modernizing the land management system and clearly articulating economic zones policy and regulations could help attract the private sector into the development of economic zones.

14. In staffs' view, promoting employment is an appropriate objective of the NSAPR II. While government's skill-development programs in the NSAPR II are useful, it is important that skills meet industry needs. As such, in staffs' view, it is necessary to form links with the private sector to develop a demand-driven skills agenda. As part of employment generation, the NSAPR II emphasizes migration and proposes a new Expatriate Welfare Bank to support this. However, instead of creating yet another state-owned bank, staffs recommend the use of existing banking channels for achieving this goal. Staffs also encourage the government to focus on entering into agreements with the governments of destination countries to facilitate safe and legal migration.

15. Staffs concur with the potential of PPPs as an important tool to close the infrastructure gap and to improve the delivery of public services. Staffs agree that wellformulated-and-executed PPPs can potentially help develop infrastructure and relieve strain on the government budget by attracting local and foreign private investment. However, for this to work, staffs recommend: (i) forming a PPP cell with adequate staffing and resources; (ii) updating the 2004 Private Sector Infrastructure Guidelines to establish a sustainable PPP framework with clear guidance on interface with the line ministries and Ministry of Finance; (iii) reforming the Private Investment Committee by redefining its role in the context of the new PPP Cell; and (iv) adopting adequate safeguards for fiscal contingencies prior to embarking on largescale PPPs. In addition, to ensure long-term financing for provision of infrastructure using PPPs, 
it is important for the central bank and the Securities and Exchange Commission to take steps for creating a vibrant market for long-term financial intermediation.

\section{Agriculture, water and land use}

16. The NSAPR II identifies agriculture and rural development as a priority area for poverty reduction, food security, employment, and growth. The main policy thrust of the strategy is to use technology for productivity gains in agriculture, livestock and fisheries sectors. The NSAPR II highlights public-private-partnerships, the potential for community-based methods in extension and fisheries management, and the recognition of the nutrition dimension of food security. In staffs' view, the rural-non farm sector - necessary for sustaining growth and reducing reduction - receives insufficient attention.

17. The set of strategies and policies for agriculture and rural development should be prioritized and sequenced. Simultaneous implementation of the proposed policies is unrealistic in view of the resource constraints, low institutional capacity, and weak coordination among the subsector ministries and agencies. The NSAPR II would have benefited from an institutional analysis for improving the performance of public institutions and developing a policy environment for stimulating agricultural performance. In addition, the interventions to foster PPPs in agricultural research, technology and marketing could be elaborated.

18. While the NSAPR II focuses on policies and strategies in the water sector, it could better address emerging challenges and opportunities. The main challenge is the weak institutional capacity for maintaining the water infrastructure, including for irrigation and for managing the use of rivers in a sustainable manner. To overcome these capacity constraints, the NSAPR II could have benefitted from identifying specific interventions to build long-term capacity of the lead water institutions. In addition, the NSAPR II could have highlighted the benefits of regional cooperation in trans-boundary rivers. Given the capacity and financial constraints in the sector, the targets set forth in the NSAPR II could be made more realistic.

19. The NSAPR II appropriately focuses on land use and sets forth modest targets. To achieve these targets, the NSPAR II could have specified measures to address the capacity constraints as well as legal and regulatory documents that need to be amended.

\section{Infrastructure and urban development}

20. Staffs concur that the vast gap between the demand and supply of energy in Bangladesh is a serious impediment to sustainable development. The proposed policies and strategies to address these problems are appropriate and the list of projects and activities proposed is comprehensive. However, many of the proposed projects are capital intensive and will have long gestation periods. The private sector could play a much more substantial role in the energy sector, but this will require that the sector's image be improved, especially with respect to financial solvency and governance. With regard to finances, staffs recommend that government rapidly implement the Power Sector Financial Restructuring Plan as well as the balance sheet cleansing activity, both of which already been approved. On Governance, staffs welcome the government's recent efforts to improve procurement transparency, economy, and efficiency, but note that continued vigilance is still required.

21. Staffs welcome the importance given to coordinating activities related to generation, transmission, and distribution of power and suggest that the gas infrastructure be included in this coordination effort. Power shortages, loss of revenue, severe staffing constraints and 
governance issues are some of the problems facing the rural electrification program. More needs to be done than simply restoring this program to its former effectiveness. Significant reforms are needed to ramp up performance to meet the challenge of universal electrification by 2020 . With respect to natural gas, staffs recommend that government take steps to rectify the severe under pricing. More market-oriented price signals will help attract the investors needed to expand domestic gas supplies. They also will encourage customers to curtail wasteful practices and use this non-renewable resource more efficiently. Finally, a power-purchase tariff geared towards renewable energy would serve to encourage private sector entry into this market.

22. The NSAPR II provides an ambitious vision for the transport sector beyond the NSAPR II period, but prioritization is essential. Construction of new infrastructure is emphasized, but the NSAPR II does not prioritize areas where resources and efforts should be concentrated. While the strategy identifies the private sector as a potential partner, its role remains unclear and there is no clear vision of how to tap into this potential. Staffs concur that more attention to road maintenance is required for increased sustainability. Poor governance in the roads sector remains a serious risk that may jeopardize government programs. Meanwhile, while the strategy identifies key actions such as the reform of Bangladesh Railways, creation of a Road Authority and a Road Fund, a greater commitment is needed to speed up these actions. Similarly, the Intermodal Transport Policy which should provide the basis for balanced development and complementarity between modes, including for facilitation of regional trade, has been in draft status for a long time and remains to be adopted.

23. The NSAPR II focuses largely on the role of government-owned telecommunications companies. While it recognizes the developments in the largely private sector-led telecommunications sector, there is a need for the NSAPR II to provide better clarity in the regulatory framework going forward, especially in the areas of license renewal and the sector's taxation regime. While the NSAPR II emphasizes the role of telecommunication companies in improving access to ICT and telecommunication services, it does not provide a strategy for how ICTs and telecommunications infrastructure will be further developed. Clarity and stability in the telecommunications regulatory environment is important to ensure sustained private investments for infrastructure and service expansion in the sector. Moreover, policy actions to increase broadband access in Bangladesh have not been discussed. In the postal sector, the NSAPR II needs to recognize changing demand for services in the sector, capacity limitations to deliver new ICT services and identify PPP-based strategies.

24. For urban development, the NSAPR II has correctly identified key challenges and strategies to address them. However, an important omission is the issue of overall urban governance, particularly in the larger metropolitan areas i.e., Dhaka and Chittagong. Strategies proposed to address the urban problems suggest that time is ripe to consider some sort of a "metropolitan government" empowered to plan, budget and monitor urban issues. In the absence of such a government the problems identified are likely to continue. As for the investments suggested, the list needs to be prioritized and more thought needs to be given to financing modalities. Particularly, how the private sector can be used to a much larger extent, both in financing and operation of urban facilities, needs to be explored. In addition, while the NSAPR II has correctly suggested the creation of a statistical database for urban planning, equal attention needs to be given to building capacity for consultative urban planning itself. Overall, in the absence of some sort of prioritization of the investments proposed, it is unclear how all of them can be achieved during the stipulated period. 


\section{B. Promoting Human Development}

\section{Education}

25. Staffs welcome the emphasis on improving quality education as well as the collaboration between the government and NGOs to achieve universal access and increased student learning in primary and secondary education. However, the target for 100 percent literacy by 2014 seems overly ambitious given the high dropout rates, limited time for classroom instruction, and an insufficient number of trained teachers. In secondary education, many of the NSAPR II recommendations are consistent with improving access and quality. Increasing enrolment and retention is a challenge, but the identified actions are focused, especially to reach the under-served populations. The use of non-formal education methods will also be important for reaching the remaining students and for addressing adult literacy. The NSAPR II also lacks discussion on the better measuring of student learning levels on a systematic and standardized basis. It is important for policymakers to have better information on student learning levels on a regular basis. Finally, the NSAPR II could have noted the cross-sectoral link with school health and nutrition that is important for students coming to school healthy and prepared to learn.

26. In staffs' view, the focus on higher and technical and vocational education and training is appropriate. The plans proposed in the NSAPR II should lead to a more demanddriven, efficient and cost-effective system. The goals of increasing the skill levels and of raising the value of human resources in the global labor market are commendable. In higher education, the challenge of ensuring adequate resources for assuring quality and expansion, as well as introducing measures to bring both innovation and accountability within universities and enhance the technical and institutional capacity of the higher education sector remain core concerns. Finally, an elaboration on the vision for digital Bangladesh in higher education would be useful.

\section{Health, nutrition and population}

27. In staffs' view, the health, nutrition and population outcomes and indicators selected in the NSAPR II are appropriate, but the targets could be made more realistic. The NSAPR II highlights progress achieved in reducing infant and child mortality, while acknowledging the need to tackle the high maternal and neonatal mortality rates. However, staffs feel that the NSAPR II could be more candid about the persistently high malnutrition rates. Bangladesh is no longer on track to meet the MDG target for malnutrition and is unlikely to meet the NSAPR II target of a 10 percentage point reduction in prevalence by 2011. Moreover, the NSAPR II recognizes that the challenge of reducing malnutrition requires coordinated multisectoral interventions on a sustained basis, but staffs recommend a clearer articulation of how the government intends to integrate and mainstream nutrition in relevant sectors.

28. The NSAPR II identifies critical areas where effective interventions and policy reforms are needed to alleviate existing constraints to achieving goals, but the strategy requires more specificity, sequencing, and setting of achievable priorities. Staffs agree that decentralization of administrative and financial authority and increased community participation can lead to improved quality of services at the local level though increased accountability and ownership. In this regard, the NSAPR II would benefit from elaborating how the incentives will be structured to ensure that service delivery responds to the needs of the poor. In addition, social insurance is identified as a strategy to finance affordable health care, but is absent from the sections covering social protection. 
Social protection, inclusion, and empowerment

29. The NSAPR II addresses the relevant areas for improving social protection and staffs welcome the attempt to consolidate individual policies of different ministries. The NSAPR II also focuses on better targeting and coverage. However, since these are complex issues, and a phased approach would be useful with detailed actions spelt out year on year. While the strategy's focus on the rural poor is appropriate, the increasing vulnerability of the urban poor also needs to be highlighted. Moreover, staffs agree that local governments have an important institutional role to play for reducing the adverse impacts of natural disasters on the poor, and that NGOs and the private sector also play a key role. Staffs recommend that the role of these actors be better defined when devising future social protection strategies. In addition, exploring more innovative approaches, such as health insurance to mitigate risk would be useful.

30. The NSAPR II acknowledges that disaster risk management is important for protecting people's livelihoods. The strategy reflects the cross-sectoral nature of disaster risk management and recognizes the importance of mainstreaming disaster risk reduction into development planning. Given its location in a seismically active area, the strategy could mainstream seismic risk reduction and mitigation in Bangladesh's disaster management strategy, devise preparedness interventions, and build capacity at various levels.

31. The NSAPR II emphasizes the needs of the most vulnerable groups in society. Staffs concur with the strategy that takes a strong rights-based approach on the vulnerability of groups which include women, children, indigenous communities, persons with disabilities, and disadvantaged and extreme poor. Staffs agree with the thrust of the proposed policies and the integrated approach. The NSAPR II would, however, benefit from concrete actions to take the proposed agenda forward, accompanied by strong baseline information and realistic targets. This highlights the need for better data collection and more effective use of gender-disaggregated data. Staffs also recommend that the proposed policy reforms be realistically costed.

\section{Governance as a Supporting Strategy}

32. The NSAPR II appropriately identifies improving governance as a key supporting strategy for achieving economic growth and reducing poverty. Staffs welcome the government's commitment to a broad, ambitious reform agenda as well as the specific policy measures laid out in the NSAPR II. However, the breadth of approach and vagueness of expected results in some areas of reform weaken the strategic focus. Given that Bangladesh's governance challenges have deep roots, achieving improvements across the board will necessarily require a long-term effort. Staffs recommend prioritization of governance initiatives based on anticipated improvements in service delivery, and through focusing improvements in sector-level governance in areas that have the highest impact on growth and poverty reduction such as infrastructure and local governance.

33. The NSAPR II properly emphasizes commitment to transparency and countering corruption through enhancing citizens' access to information, e-governance, and sustaining the work of the Anti-Corruption Commission (ACC). Requirements for public authorities to release information and promotion of e-governance have the potential to change the way in which the citizens interface with the state. While the NSAPR II notes that the passage of the Right to Information Act marked a major step towards improving governance, it does not outline how to realize the Act's potential to create incentives for better governance. Staffs recommend that the Act be operationalized through passage of relevant rules and regulations and building capacity for public institutions to implement the Act. Staffs welcome the NSAPR II's emphasis on promoting 
e-governance and using ICT for improving efficiency of public services while reducing opportunities for corruption. The NSAPR II also commits to enforcing anti-corruption measures and sustaining the ACC as an independent body. Staffs recommend that the ACC retain robust investigative and prosecutorial powers, and be given the space to operate independently.

34. The NSAPR II proposes specific actions to deepen the ongoing public financial management reform, a key area for improving governance. In particular, the NSAPR II emphasizes rolling out medium term budget framework to all 49 ministries for strategic and prioritized resource allocation, increasing parliamentary oversight and for following up on annual audits. However, in staffs' view, the NSAPR II could have provided specific measures for (i) improving revenue mobilization as expected in the NSAPR II's costing table (apart from the recent work on modernizing tax administration, starting with VAT), (ii) integrating capital and recurrent budgets, and (iii) ensuring the independence of the Comptroller and Auditor-General by promulgating the Audit Act, all of which are included in the government's public financial management reform strategy.

35. The NSAPR II appropriately focuses on strengthening local government, which in turn can lead to better delivery of public services. Given that the current high degree of centralization has not led to desired service outcomes, there is scope for decentralization to create better incentives for delivery of public services at the local and metropolitan levels. The NSAPR II identifies several steps towards improving the performance of local government and making it more accountable to local populations. Staffs recommend a clearer articulation of the overall legal framework for local and metropolitan governments' functional responsibilities and the allocation of corresponding human and financial resources.

36. The strategic goals and policy actions in the NSAPR II for Digital Bangladesh present an ambitious agenda for implementation. The NSAPR II has documented the potential for using ICTs to enhance the quality of governance and delivery of services. Given the vast policy agenda and investments needed, staffs recommend prioritization of activities, while simultaneously undertaking key enabling actions in the areas of institutional arrangements, legal and regulatory framework, infrastructure and services for e-governance. Staffs also urge addressing of key challenges to achieving the goals for Digital Bangladesh which will require change management, project management and IT skills within and outside government agencies. Further, with the substantial investments that will be made in a national identification card program, more thought needs to be given to how the program can be leveraged for more effective delivery of citizen and business services. Staffs recommend greater clarity on how the private sector can be utilized to a much larger extent, both in financing and delivering on the Digital Bangladesh agenda. Staffs also encourage greater coordination between initiatives planned under Digital Bangladesh and sectoral interventions.

\section{Environment and Climate Change}

37. The NSAPR II correctly emphasizes environmental sustainability as a key supporting strategy to achieve growth and poverty reduction. In Bangladesh, the environmental challenges posed by increasing population pressure and rapid unplanned urbanization are being further compounded by climate variability. The NSAPR II calls for both an enhanced financial allocation and, more importantly, a substantial upgrading of the capacity, convening and coordination role of the Ministry of Environment and Forest. The current low budgetary allocation of the Ministry (Tk. 0.87 billion or 0.3 percent of total ADP) is an indicator of the Ministry's limited capacity and weak convening power, which is a major constraint in administering an expanding set of interlinked actions to meet the outlined challenges. 
38. The policies and strategies are comprehensive, covering an integrated environment and climate change agenda, with a national government program to take up sectoral and multi sectoral measures for arresting and preventing environmental degradation, scaling up climate proofing of existing vulnerable infrastructures and undertaking of adaptation programs. The sequencing suggested for the policy, planning, regulations, and capacity building elements is appropriate. However, further delegation of responsibilities to proper stakeholders and Ministries based on their mandate and comparative advantage would enhance effectiveness. The capacity building elements included in the NSAPR II largely focus on enhancing awareness and research but it should also include institutional capacity building. There are 11 strategic goals in the NSAPR II; however important goals including climate change adaptation, reforming institutions to improve effectiveness are not included and may hinder effective implementation of the strategy and affect the main objective of poverty reduction.

39. The key challenge is to strengthen the capacity of the lead Ministry as well as to improve its convening authority and broaden its focus. Targets are ambitious, and deservedly so, in view of the increase of industrialization, population density, commercial activities, urbanization, and the country's vulnerability to climate change. The challenge for the government is to match the proposed strategy, policy and outcomes with appropriate institutional arrangements, effective monitoring, and adequate funding.

\section{Implementation, Monitoring and Evaluation}

40. The implementation arrangements and monitoring and evaluation (M\&E) system are clearly articulated in the NSAPR II, and the focus now needs to shift towards building capacity. The NSAPR II recognizes the importance of the M\&E system to track progress of the reform process. The institutional framework is described in detail to clarify accountability and responsibilities of various agencies in the government. Also, Annex 3 provides an exhaustive list of policy goals with corresponding concrete monitoring indicators. While clear accountability lines and concrete indicators are important steps in creating a solid M\&E system, they also require adequate capacity to monitor, analyze, validate and disseminate information on inputs, outputs, and outcomes at every level. The NSAPR II recognizes the need for capacity building, but it does not directly address the existing capacity gaps. Assessing the adequacy of the proposed M\&E arrangements requires a candid assessment of the existing capacity constraints. Staffs recommend that a capacity building strategy and action plan be developed to support the proposed M\&E arrangements, both at the systemic and human resources levels.

41. Moving forward, it is an urgent priority to clearly identify which monitoring instruments will be used to create the indicators suggested, and to identify the corresponding implementation agencies. The NSAPR II indicates that Household Income and Expenditure Survey and other surveys would be used to create monitoring indicators, but even recognized sources of data are not specified in Annex 3. In addition, the frequency and regularity, implementation agencies, and financial sources of survey instruments need to be decided since clarification of these is crucial for ensuring the reliability and feasibility of the $M \& E$ system. Given the importance of the M\&E system to track progress of reforms under the NSAPR II, staffs recommend that the progress in identification of monitoring indicators, survey instruments, and implementation agencies be reported annually. 


\section{Conclusion and Issues for Discussion}

42. Staffs consider the NSAPR II a starting point for Bangladesh to move forward in addressing challenges to growth and poverty reduction. The strategy is comprehensive and addresses all issues that impede sustainable development in Bangladesh. It provides a starting point for donors to harmonize and align their assistance. Given the numerous development challenges facing Bangladesh, staffs urge that the implementation of NSAPR II and the formulation of the Sixth Five Year Plan be guided by continuous learning and analytical work.

43. The NSAPR II would have benefited from a candid assessment of past achievements and progress made under NSAPR I. Some lessons from implementation of NSAPR I and recommendations of the previous JSAN have been incorporated in the NSAPR II, but they could have been spelled out more clearly. The NSAPR II would have benefited from a discussion of the lessons learned from implementing NSAPR I and how they helped shape the NSAPR II. Such an evaluation would also be of help in formulating the Sixth Five Year Plan.

44. Staffs recommend a prioritized and sequenced implementation of the programs in the NSAPR II period. The NSAPR II identifies resource needs of around US $\$ 12.5$ billion from external sources, which implies a considerable resource gap to address all the priorities identified in the NSAPR II. Staffs consider that priorities for accelerated and inclusive growth include: increasing tax revenue and the quantity and quality of public investments; enhancing the business environment for the private sector; reducing environmental degradation and vulnerability to climate change; improving social service delivery including through decentralization; and enhancing accountability. These are medium-to-long term priorities which go beyond the period of the NSAPR II and would have to be addressed by the forthcoming Sixth Five Year Plan.

45. The NSAPR II faces implementation risks. Low implementation capacity makes the list of policy measures identified in the NSAPR II overwhelming. These measures need streamlining for decision-making, implementation, and monitoring purposes. Similarly, more attention needs to be devoted to simplifying the M\&E framework, while developing the capacity to expand the amount, quality, and timeliness of information. Wavering commitment to reforms combined with weak governance (which affects the effectiveness of expenditure) also pose challenges to the implementation of NSAPR II. Uncertainty on continuation of political support for regional cooperation can truncate its likely gains. Finally, slow progress in decentralized decision-making and local empowerment can limit improvements in delivery of services.

46. Issues for discussion. In considering the authorities' NSAPR II and the associated JSAN, do Executive Directors agree with main areas identified by staffs for further strengthening? Do Executive Directors agree with the main risks to implementation identified above? 